CERE Working Paper, 2021:4

\title{
Enhancing the informational nudge of energy labels: Evidence from a DCE in New Delhi
}

\author{
Charu Grove, Sangeeta Bansal, and Adan L. Martinez-Cruz
}

The Centre for Environmental and Resource Economics (CERE) is an inter-disciplinary and inter-university research centre at the Umeå Campus: Umeå University and the Swedish University of Agricultural Sciences. The main objectives with the Centre are to tie together research groups at the different departments and universities; provide seminars and workshops within the field of environmental \& resource economics and management; and constitute a platform for a creative and strong research environment within the field.

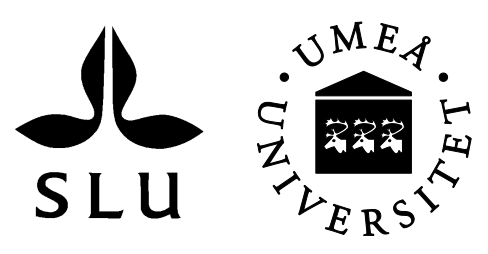




\title{
Enhancing the informational nudge of energy labels: Evidence from a DCE in New Delhi
}

\section{Charu Grover}

\author{
charu.grover85@gmail.com \\ Shaheed Bhagat Singh College, University of Delhi, India \\ Centre for International Trade and Development, Jawaharlal Nehru University, India
}

\section{Sangeeta Bansal}

sangeeta.bansal7@gmail.com

Centre for International Trade and Development, Jawaharlal Nehru University, India

\section{Adan L. Martinez-Cruz}

adan.martinez.cruz@slu.se

Department of Forest Economics and Centre for Environmental and Resource Economics (CERE), Swedish University of Agricultural Sciences (SLU), Sweden

Centre for Energy Policy and Economics (CEPE), ETH-Zurich, Switzerland

Department of Economics, Centro de Investigacion y Docencia Economicas (CIDE), Mexico

February 8, 2021 
Enhancing the informational nudge of energy labels in New Delhi

\begin{abstract}
India's contribution to global $\mathrm{CO}_{2}$ emissions makes it a priority case for policy makers worldwide. The Indian government is considering the adoption of energy labels for new passenger cars to tackle $\mathrm{CO}_{2}$ emissions. This paper's first aim is to asses New Delhi's car buyers' preferences for cars displaying energy labels. To do so, a discrete choice experiment (DCE) has been designed to document both WTP for energy efficiency (212 USD for one kilometer per liter) and WTP for the best efficiency label (4.93 thousand USD). The informational nudge embedded in a labeling system may not be enough to boost uptake of efficient cars. Thus this paper investigates the potential of combining a labeling system and car driving restrictions. Via a split-sample approach, this paper documents an increase of 2.55 thousand USD in stated WTP for the best efficiency label. This number can be interpreted as reflecting the costs imposed by the driving restrictions on car drivers. Under this interpretation, 2.55 thousand USD fall within the range of estimations reported in previous studies. The results in this paper suggest that a combination of driving restrictions and a labeling system may deliver an increase in energy efficient cars in New Delhi.
\end{abstract}

Keywords: energy labeling system; driving restrictions; willingness to pay; discrete choice experiment; split-sample approach; New Delhi. 
Enhancing the informational nudge of energy labels in New Delhi

\section{Introduction}

Growing concerns about climate change have led countries worldwide to adopt policies aiming to decrease $\mathrm{CO}_{2}$ emissions from human activities. In this context, India's relative contribution to $\mathrm{CO}_{2}$ emissions makes it a priority case for national and international policy makers. In 2018, India accounted for $25 \%$ of the total increase in global $\mathrm{CO}_{2}$ emissions which represented a $7 \%$ increase with respect to $2017(\mathrm{BP}, 2019)$.

In particular, the global transportation sector has been identified as an important generator of $\mathrm{CO}_{2}$ emissions. In the European Union (EU), 250 million passenger cars contribute to $14 \%$ of the final energy use and to $12 \%$ of the fuel-related $\mathrm{CO}_{2}$ emissions (Haq \& Weiss, 2016). In India, the transportation sector's contribution to total air pollution has been reported as high as $72 \%$ (Goyal et al., 2006).

In megacities of emerging economies, the negative effects from air pollution on human health adds to the relevance of combating $\mathrm{CO}_{2}$ emissions from the transportation sector. India becomes a priority case under this category as well because it contains six out of the ten most polluted cities in the world (IQ-Air, 2019). In particular, New Delhi has recently experienced air pollution levels surpassing up to 30 times the level that the World Health Organization (WHO) considers safe (Schultz et al. 2017; Irfan, 2019) which has taken its toll on life expectancy - around 10 years or 7 years would be gained if $P M_{2.5}$ levels reached WHO standards or national standards, respectively (Saraswat \& Bansal, 2020).

India is currently considering the introduction of a mandatory labeling system as part of a wider effort to decrease emissions from the transportation sector (Global Fuel Economy Initiative, 2020). This system would provide information about relative energy efficiency to consumers by classifying new passenger cars into five categories. The categories would be represented by stars - with one star reflecting the worst energy efficiency category and five stars reflecting the best energy efficiency category. A car displaying an energy label would provide private benefits to consumers in the form of fuel cost savings and public benefits in the form of reduced $\mathrm{CO}_{2}$ emissions per kilometer driven.

In this context, this paper's first aim is to asses New Delhi's car buyers' stated preferences for passenger cars displaying energy efficiency labels. By means of a discrete choice experiment (DCE), respondents are presented to choice tasks that describe three labeled alternatives - a high star car (best efficiency label), a moderate star car (second best efficiency label), and a status quo alternative. The alternatives have been described in terms of five attributes: mileage, engine displacement, transmission, price, and social network. All but social network are standard attributes of a car. Following Rasouli \& Timmermans (2016), we test for the possibility of a peer-pressure social - the attribute is phrased as the percentage of people in the respondent's social network that drive the car described in the choice task.

Our DCE is designed to disentangle preferences for an energy efficiency label in itself and preferences for mileage - it contains choice tasks in which cars with different efficiency labels have identical mileage, resembling a discontinuity. This 
Enhancing the informational nudge of energy labels in New Delhi

design is motivated by previous studies documenting that the price paid for a car displaying an energy label goes above and beyond the fuel costs savings derived from the increase in fuel efficiency. For the Swiss case, for instance, Alberini et al. (2016) analyze revealed preferences data and reports that the value of the energy efficiency label falls within $6 \%$ to $11 \%$ of a car's price.

Based on our DCE, this paper documents that car drivers in New Delhi value a gain in efficiency of one kilometer per liter in around 212 US dollars an amount close to the 280 US dollars in fuel cost savings over a 10-year period which is the average lifetime of a car in New Delhi. In addition, and consistently with results reported by Alberini et al. (2016), car drivers are willing to pay a premium for the best and the second best energy labels of, respectively, 25\% and $19 \%$ of a car's price.

A second aim of this paper arises from the consideration that the informational nudge embedded in an energy label may not be by itself enough to translate stated preferences into actual uptake of efficient cars. When it comes to appliances, energy labels have been documented as successful in nudging consumers in developed countries (Haq \& Weiss, 2016). However, evidence is less promising for the case of car labels and suggests that an energy label does not stand by itself. For instance, in a survey of ten EU countries, $45 \%$ of respondents were not familiar with car labels and $40 \%$ felt that the label was not easily recognizable (Haq \& Weiss, 2016). Focusing on Main, USA, Noblet et al. (2006) strongly recommend educational campaigns if policy makers expect energy labels to be effective. In France, a car labeling system seem to have had an impact on its own as an informational device but a significant impact can only be attached when the labels were combined with fiscal incentives (see European Commission, 2016).

Thus a policy of energy labeling in India may need to be accompanied by an additional instrument. Policy makers in developed economies have strengthened the informational nudge of a labeling system with fiscal instruments - usually taking the form of subsidies or tax breaks (Galarraga et al. 2020. However, resource constrained governments in emerging economies may find difficult to mobilize fiscal resources. In particular, the government of India has not considered fiscal instruments to boost the uptake of efficient cars 11 Thus we explore the potential of a regulation that imposes restrictions on the days a car can be driven. This type of regulation was implemented in New Delhi in January and April 2016, and again in November 2019. During these periods, cars could circulate depending on the number of their license plate. Cars with even numbers were allowed to circulate only on even dates, and similarly the cars with odd number license plate on odd dates ${ }^{2}$ This type of regulation is not uncommon among emerging economies -e.g. driving restrictions have been enforced in Mexico City since early 1990s via a program called Hoy No Circula.

\footnotetext{
${ }^{1}$ Since 2014, India has implemented subsidies to electric vehicles (Bhattacharya, 2014). However, the scope and success of this policy remains limited because, among other reasons, charging infrastructure is yet to be available in India

${ }^{2}$ Arguably, this regulation contributed to the decrease of $P M_{2.5}$ from $316 \mu \mathrm{g} / \mathrm{m}^{3}$ to 223 $\mu \mathrm{g} / \mathrm{m}^{3}$ during the second week of January 2016 (Centre for Science and Environment, 2016)
} 
Enhancing the informational nudge of energy labels in New Delhi

Since New Delhi residents are familiar with restrictions on the day they can drive, we incorporate a driving restriction scenario in our DCE as an instrument accompanying the labeling system. Thus the second aim of this paper is to assess whether car driving restrictions tied to a labeling system can be expected to boost the purchase of fuel efficient cars in New Delhi. We test for this possibility by implementing a novel approach. Before the DCE was presented to respondents, half of our sample was randomly assigned to a driving restriction scenario according to which they were told that the government is considering the implementation of restrictions on the number of days a car can be driven weekly unless the car displays the label reflecting the best fuel efficiency performance. Effectively, the phrasing of our scenario provides an incentive to buy an efficient car in the form of an exemption from driving restrictions.

Results from this split-sample approach support the claim that driving restrictions tied to a labeling system seem a promising policy to increase the uptake of fuel efficient cars in New Delhi. The split-sample approach yields an increase in respondents' stated Willingness to Pay (WTP) for the best efficiency label - from 4.93 thousand US dollars to 7.48 thousand US dollars. To put these numbers in context and judge their magnitude, it is convenient to interpret them as regulatory costs - i.e., the extra 2.55 thousand US dollars represent the amount that respondents are willing to pay for an energy label that would exempt them from the driving restrictions. Under this interpretation, our 2.55 thousand US dollars come close to the 2.96 thousand US dollars in regulatory costs generated by the Mexican Hoy No Circula - this number results from the WTP estimates obtained via a contingent valuation implemented by Blackman et al. (2018) in Mexico City.

Importantly for the internal validity of this exercise, the WTP for other attributes in our DCE is not impacted by the split-sample strategy — which we consider evidence supporting the claim that respondents understood the driving restriction scenario and reacted accordingly in the stated preference space. Additionally, we simulate market share curves for cars with best efficiency label and cars with second best label under two scenarios-with driving restrictions and without driving restrictions. These curves show a shift in the market share for cars with best efficiency label under the driving restriction scenario and no change in market shares for cars with second best efficiency label under the two scenarios providing further evidence of internal validity.

This paper contributes to the stated preferences and energy policy literatures in four ways. First, to the best of our knowledge, no previous study has designed a DCE that disentangles preferences for energy efficiency and preferences for an energy label - and only a few revealed preferences studies have separated such preferences (see Alberini et al. 2016, 2019). Second, by interpreting results from the split-sample approach as the WTP to avoid driving restrictions, this paper belongs to the nascent stated preferences literature estimating regulatory costs from policies tackling car usage (see Blackman et al., 2018; Blackman \& Qin, 2018). Third, we are able to simulate market share curves for cars with specific attributes under different policy scenarios. Fourth, this study is among the first ones implementing DCEs to explore preferences for energy labels in India 
Enhancing the informational nudge of energy labels in New Delhi

- to the best of our knowledge, the only previous study focuses on preferences of consumers in Mumbai for energy labels in air conditioners and refrigerators (Jain et al., 2018).

\section{Previous studies}

Under the assumption that some consumers may lack information or may hold incorrect beliefs about the fuel costs implicit in the purchasing of a car, the purpose of fuel efficiency labels is to provide information that helps these consumers in their purchasing decisions.

This paper's first aim is to investigate whether New Delhi's car drivers would attach value to such an informational device and whether this value can be thought as a premium on top of the fuel efficiency value derived from fuel cost savings. To the best of our knowledge, the disentangling of such values has been explored by only a few revealed preference studies and by none stated preferences study ${ }^{3}$

Alberini et al. (2016) study a labeling system introduced in Switzerland in 2003. This system assigns to new passenger cars one of seven labels based on CO2 emissions - from A (best) to G (worst). Given data on all cars approved for sale in Switzerland from 2000 to 2011, they estimate hedonic regressions and results suggest the presence of a fuel-economy premium. However, due to the collinearity between the label and actual fuel efficiency, hedonic regressions are not able to yield insights on whether the fuel-economy premium is partially due to the fuel economy label. To circumvent this issue, they turn to a sharp regression discontinuity design based on the mechanism used by the government to assign cars to the fuel economy label. This strategy yields an effect from the best efficiency label that falls in the range of $6 \%$ to $11 \%$ of a car's price. Matching estimators yield an average effect of $5 \%$.

Alberini et al. (2019) put together a dataset documenting the characteristics, prices, and monthly sales of conventional diesel and gasoline, plus hybrids, plugin hybrids and pure-electric passenger cars from January 2011 to September 2017 in eight European countries that account for more than $80 \%$ of all new car sales in the European Union. By means of hedonic regressions, they document that car drivers assign value to fuel efficiency of hybrid and battery-electric vehicles. They implement a matching strategy at the strata level to document the presence of a battery premium. For regular hybrids, this premium is 2,000 Euros or less. The premium is large for plug-in hybrids (10,000 Euros) and BEVs (12,000 Euros), and is not explained away by the additional weight and

\footnotetext{
${ }^{3}$ This is not to say that DCE have not explored the WTP for fuel efficiency or for fuel efficiency labels. The distinction we make is that previous DCE have not aimed to separating preferences for efficiency labels and for fuel efficiency itself. Previous DCE studies focusing on WTP for fuel efficiency include Achtnicht (2012); Leard (2018). Previous DCE studies focusing on WTP for fuel efficiency labels or information include Daziano et al. (2017); Ziegler (2012). However, ours is the first DCE to explore WTP for fuel efficiency or fuel efficiency labels in India.
} 
Enhancing the informational nudge of energy labels in New Delhi

size typical of these cars (due in part to the battery), or the fact that many plug-ins are sports utility vehicles.

This paper's second aim is to investigate whether the impact of the labeling policy on the demand for fuel efficient cars is enhanced when combined with driving restrictions. In pursuing this aim, this paper contributes to a nascent stated preferences literature documenting regulatory costs derived from driving restrictions. This paper implements a split-sample approach in which half of the respondents are presented to a driving restrictions scenario, and calculates the extra WTP for the best efficiency label with respect to the case in which respondents are not presented to a driving restrictions scenario. This extra WTP can be interpreted as the amount of money car drivers are willing to pay to avoid being subject to driving restrictions -i.e. an estimate of regulatory costs.

To the best of our knowledge, Blackman et al. (2018) and Blackman \& Qin (2018) are the two previous studies documenting regulatory costs from driving restrictions via stated preferences methods. Blackman et al. (2018) highlight that little is known about the cost of environmental regulations that target households. Partly, this is due to methodological and data challenges which is a reason to turn to stated preferences methods. They use a contingent valuation protocol to measure the regulatory costs of Mexico City's Hoy No Circula which prohibits vehicles from being driven one day each week. Their protocol asks respondents to report their WTP for a label to avoid the driving restrictions. They find substantial regulatory costs: up to 130 USD per vehicle per year, which represents $1 \%-2 \%$ of drivers' annual income and implies total costs of 617 USD million per year. Implementing a very similar protocol in Beijing, China, Blackman \& Qin (2018) regulatory costs falling within 53 USD to 107 USD per driver per year, which represents $0.5 \%$ to $1 \%$ percent of annual income, and 245 million USD to 493 million USD per year for all drivers.

\section{Context}

Energy consumption in India is on the rise. From 2013 to 2017, India's energy consumption has increased at an average rate of 5.3\%. India's share in global energy consumption reached 5.6\% in 2017 (BP, 2018). The Energy Information Administration (EIA) has projected that India and China together will account for around half of the global energy demand growth by 2040. This trend is a matter of concern as energy consumption adversely affects environment and increases green house gas (GHG) emissions - which are also on the rise in India, with an increase of $4.6 \%$ with respect to 2016 (Olivier et al., 2017).

New Delhi, the national capital of India and one of the 46 megacities in the world, is a major generator of carbon emissions in the country - with emissions of 37.91 million tones of $\mathrm{CO}_{2}$ equivalent in 2014 (Sharma \& Dikshit, 2016). In recent years, New Delhi has become an illustration of the dilemma that air pollution imposes on megacities. Every November since 2017, with alarmingly regular occurrence, air pollution has surpassed up to 30 times the level that the 
Enhancing the informational nudge of energy labels in New Delhi

World Health Organization (WHO) considers safe (Schultz et al., 2017, Irfan, 2019). During these episodes, $P M_{2.5}$ has climbed to more than $700 \mu \mathrm{g} / \mathrm{m}^{3}$ which is hazardous to breath.

While several factors are to blame ${ }^{4}$ emissions from vehicles are at the core of the issue. Around $72 \%$ of these emissions are due to the transportation sector Goyal et al. (2006). A recent increase in vehicle ownership in New Delhi has contributed to these emissions - in 2018, there were more than 10 million vehicles in New Delhi which represented a $5.81 \%$ growth from the previous year (Economic Survey of Delhi, 2019). To put some context, the total number of registered vehicles in 2016 was larger than the combined number of registered vehicles in Chennai and Mumbai (7.7 Million) (Government of India, 2018).

India has implemented policies aiming at reducing emissions from the transportation sector. In a landmark move, the Supreme Court of India issued orders that the entire public transport system in Delhi be switched from diesel to Compressed Natural Gas by 2001 (Goyal \& Sidhartha, 2003). In 2015, the National Green Tribunal banned diesel vehicles older than 10 years from circulating in New Delhi (Goel \& Pant, 2016). In 2015, the Ministry of Power issued average fuel consumption standards based on kilometers per litre $(\mathrm{kmpl})$ for the passenger cars (Bureau of Energy Efficiency, 2020). These norms will be binding for car manufacturers in two phases - 2016-2017 and 2022-2023. The goal is to improve fuel efficiency (mileage) by $10 \%$ in the first phase and by $30 \%$ in the second phase. With the implementation of these new fuel efficiency norms, $\mathrm{CO}_{2}$ emissions are projected to go from 142 gram per km in 2010-11 to 113 gram per $\mathrm{km}$ in 2022 (Bureau of Energy Efficiency, 2020).

In this context, the Bureau of Energy Efficiency plans to introduce a labeling system that would provide information by rating all the new cars in terms of fuel efficiency (Global Fuel Economy Initiative, 2020). This label system would classify cars among five categories. The categories would be represented by stars - with one star reflecting the worst fuel efficiency category and five stars reflecting the best fuel efficiency category. The display of an efficiency label is expected to provide private benefits to consumers in the form of fuel cost savings and public benefits in the form of reduced GHG emissions per kilometer driven.

\section{Theoretical and empirical approach}

The Random Utility Model (RUM) provides theoretical support to the empirical analysis of discrete choice experiments (see Train, 2009). The departure point of the RUM is that, when faced to $J$ mutually exclusive alternatives, individual $i$ chooses the alternative that provides him/her with the highest utility. An individual's indirect utility from each alternative is denoted as $U_{i j}$ for $i=1,2, \ldots, I$ and $j=1,2, \ldots, J$. The individual is assumed to know his/her own

\footnotetext{
${ }^{4}$ Air pollution in New Delhi results from a combination of emissions from vehicles, industrial pollution, coal combustion, biomass combustion, road dust, waste burning/incineration, brick kilns, and oil combustion (Goel \& Pant 2016). In recent years, crop burning has been associated with the highest episodes of air pollution (Irfan, 2019).
} 
Enhancing the informational nudge of energy labels in New Delhi

utility function with certainty. The researcher, however, cannot fully observe each $U_{i j}$. Thus, from the researcher's point of view and once a linear indirect utility function is assumed, $U_{i j}$ can be expressed as

$$
U_{i j}=V_{i j}+\epsilon_{i j}=\beta^{\prime} x_{i j}+\epsilon_{i j}
$$

where $V_{i j}$ is the component observed by the researcher; $x_{i j}$ is a $(M+1) X 1$ column vector denoting $M$ alternative-specific attributes and the alternativespecific intercept; $\beta$ is a $(M+1) X 1$ column vector representing the alternativespecific intercept, and the preferences for the alternative-specific attributes; and $\epsilon_{i j}$ represents the purely random heterogeneity that the researcher is unable to observe.

If an individual chooses the alternative associated to the highest utility, then the individual $i$ chooses $U_{i}^{\max }$, where

$$
U_{i}^{\max }=\max \left\{U_{i 1}, U_{i 2}, \ldots \ldots ., U_{i J}\right\}
$$

The willingness to pay (WTP) for the alternative associated to the highest utility is expressed as the monetary value of the utility derived from $U_{i}^{\max }$, i.e.,

$$
W T P_{i}=\frac{U_{i}^{\max }}{\beta_{p}}
$$

where $W T P_{i}$ is individual $i$ 's WTP; and $\beta_{p}$ is the price preference parameter. Under the assumption that indirect utility is linear in attributes, including income, $\beta_{p}$ is the negative of the marginal utility from income.

Under the assumptions embedded in equation (1), a researcher cannot observe $U_{i}^{\max }$ as defined in equation (2). A researcher can only make statements in terms of expected utilities which are calculated over the error term $\epsilon_{i j}$, i.e.

$$
E\left(U_{i}^{\max }\right)=E_{\epsilon}\left[\max \left\{V_{i 1}, V_{i 2}, \ldots \ldots ., V_{i J}\right\}\right]
$$

Under the assumption that $\epsilon_{i j}$ follow a type I extreme value distribution, the expected maximum utility can be calculated through the logsum formula 5 i.e.

$$
E\left(U_{i}^{\max }\right)=\ln \sum_{j=1}^{J} \exp \left(V_{i j}\right)
$$

Accordingly, statements involving welfare measures are made in expected terms. For a before $(b)$ and an after $(a)$ situations - where after implies a change in the available alternatives-, the expected value of the compensation

\footnotetext{
${ }^{5}$ Pioneer derivations of the logsum formula were independently developed by Ben-Akiva (1973) and McFadden 1973.
} 
Enhancing the informational nudge of energy labels in New Delhi

variation $(\mathrm{CV})$ due to the change in individual $i$ 's utility is expressed as

$$
\begin{aligned}
E_{\epsilon}\left(C V_{i}\right) & =\frac{1}{-\beta_{p}}\left(E_{\epsilon}\left(U_{i}^{\max , a}\right)-E_{\epsilon}\left(U_{i}^{\max , b}\right)\right) \\
& =\frac{1}{-\beta_{p}}\left(\ln \sum_{j=1}^{J} \exp \left(V_{i j}^{a}\right)-\ln \sum_{j=1}^{J} \exp \left(V_{i j}^{b}\right)\right)
\end{aligned}
$$

The marginal willingness to pay (MWTP) can be derive from equation (5) as follows. Assume attribute $q$ changes in a non-marginal fashion across all alternatives -i.e. $q^{a}=q^{b}+\Delta q$ is the level of $q$ after $\Delta q$ has been added to $q^{b}$. Introduce the change in $q$ in equation (5) and, because such a change occurs across all alternatives, factor it 6 . The expected CV can be expressed as follows

$$
E_{\epsilon}\left(C V_{i}[\Delta q]\right)=-\Delta q \frac{\beta_{q}}{\beta_{p}}
$$

where $\beta_{q}$ is the marginal utility from $q$.

Equation (6) reduces to the WTP for a marginal change across alternatives when $\Delta q=1-$ i.e. when the change in $q$ is marginal, and

$$
E_{\epsilon}\left(M W T P_{i}\right)=-\frac{\beta_{q}}{\beta_{p}}
$$

Equation (7) can be interpreted as the ratio of the marginal utility from the attribute that changes and the negative of the marginal utility from income.

Empirical estimations of the parameters required in the calculation of the expected MWTP (i.e. $\hat{\beta}_{q}$ and $\hat{\beta}_{p}$ ) can be obtained via a conditional logit econometric specification. The departure point of this empirical model is the same as to establish the theoretical expectations of the welfare measures under discrete choice modelling -i.e. $\epsilon_{i j}$ is distributed according to a type I extreme value distribution. Under this assumption, the probability that individual $i$ chooses alternative $j$ is expressed as follows

$$
\begin{aligned}
P_{i j} & =\operatorname{Pr}\left[V_{i j}+\epsilon_{i j}>V_{i k}+\epsilon_{i k} \forall k \neq j\right] \\
& =\operatorname{Pr}\left[\epsilon_{i j}>V_{i k}-V_{i j}+\epsilon_{i k} \forall k \neq j\right] \\
& =\frac{e^{V_{i j}}}{\sum_{k \in J} e^{V_{i k}}}=\frac{e^{\beta^{\prime} x_{i j}}}{\sum_{k \in J} e^{\beta^{\prime} x_{i k}}}
\end{aligned}
$$

A conditional logit (CL) specification faces two limitations to model empirical discrete choice data (Train, 2009). First, a CL can represent systematic variation (i.e. taste variation that is related to observed characteristics) but not random taste variation (i.e. differences in tastes that cannot be linked to observed characteristics). Second, the estimation of the CL probabilities implies

\footnotetext{
${ }^{6}$ Further details can be found in Haab \& McConnell (2002).
} 
Enhancing the informational nudge of energy labels in New Delhi

proportional substitution across alternatives - more flexible, more realistic patterns cannot be fitted with a CL model. 7

The random parameters logit (RPL) results from adapting the CL model to incorporate non-systematic heterogeneity in preferences and discard the proportional substitution across alternatives. The RPL turns out to be a highly flexible model that can approximate any random utility model (McFadden \& Train, 2000).

The RPL probabilities are the integrals of standard logit probabilities over a density of parameters. That is, keeping in mind equation (8), a RPL is a model whose choice probabilities can be expressed in the following form

$$
P_{i j}=\int \frac{e^{\beta^{\prime} x_{i j}}}{\sum_{k \in J} e^{\beta^{\prime} x_{i k}}} f(\beta) d \beta
$$

where $f(\beta)$ is a density function. The RPL probability is a weighted average of the logit formula evaluated at different values of $\beta$, with the weights given by the density $f(\beta)$. In statistical terms, the weighted average of several functions is called a mixed function. Consequently, a RPL is a mixture of the logit function evaluated at different $\beta$ 's with $f(\beta)$ as the mixing function.

\section{$5 \quad$ Survey methods and Data}

\subsection{Discrete choice experiment}

Table 1 lists the attributes of our discrete choice experiment (DCE) - mileage, engine displacement, transmission, social network, and price-, their levels, and the expected sign of the corresponding preference parameter. These attributes were identified via a series of focus groups, and a review of previous studies estimating the value of fuel efficiency - and they were piloted as well.

Mileage is expressed as kilometers per liter $(\mathrm{kmpl})$. In a DCE presenting unlabeled alternatives, mileage itself is the natural candidate to provide information about fuel efficiency - and the WTP associated to it would capture the marginal benefits from a unit of efficiency. In contrast, our DCE has been designed to distinguish the WTP for mileage and the premium that drivers may assign to a fuel efficiency label ${ }^{8}$

In order to separately estimate the preferences for mileage and the preferences for a fuel efficiency label, a DCE needs to balance two features. On one hand, a realistic approach implies that mileage is completely collinear with the labels of the alternatives - i.e. the best label should always have better mileage. On the other hand, an ideal DCE would yield non-realistic scenarios that may seem pointless to attentive respondents - e.g. a car with the best efficiency label having worse mileage than a car with the second best efficiency label.

\footnotetext{
${ }^{7} \mathrm{~A}$ third limitation is that a CL is not fitted to capture correlation over time (Train, 2009).

${ }^{8}$ The reasons for this extra WTP can be behavioral or not. In a companion paper, we explore this point via latent class analysis.
} 
Enhancing the informational nudge of energy labels in New Delhi

A compromise between the two features, therefore, implies that alternatives in the DCE should be realistic at the same time that collinearity is only partial. Consequently, our DCE presents choice tasks in which cars with different efficiency labels have identical mileage. In particular, our DCE displays three alternatives that are labeled, respectively, as high star car (5 or 4 stars), moderate star car (3 stars), and unlabeled car (status quo alternative). Respondents are told that fuel efficiency of high star cars is better than moderate star cars' efficiency. However, when the choice tasks are designed, mileage is allowed to take values $20 \mathrm{kmpl}$ and $24 \mathrm{kmpl}$ for high star cars, and $16 \mathrm{kmpl}$ and $20 \mathrm{kmpl}$ for moderate star cars. That is, both categories of fuel efficiency intersect at $20 \mathrm{kmpl}$. In this way, we keep realism as much as possible without presenting completely collinear alternatives. Notice that another way to conceptualize this design is as resembling a discontinuity -i.e. as if one of two cars with identical mileage is barely (maybe mistakenly) classified within a different efficiency category.

The rest of attributes, with exception of social network, reflect standard characteristics of a car. Engine displacement measures the engine's power and is expressed as the size of the engine in cubic centimetres (cc). This attribute takes three possible values - upto 1000cc, 1000-1500cc and more than $1500 \mathrm{cc}$. A cars' transmission can be automatic or manual. In automatic transmission, gears automatically change depending on car and engine speed. In contrast, in manual transmission, driver changes gears manually using clutch pedal as per the driving needs. The price attribute is described as percentage increases $-10 \%, 20 \%, 30 \%, 40 \%$ and $50 \%$ - with respect to a reference price. At the beginning of our survey, respondents were asked to provide the price at which they intend to purchase a car in the near future. We take this reported price as the reference from which price increases are calculated.

Following Rasouli \& Timmermans (2016), we test for the possibility of a peer-pressure effect via the social network attribute. This attribute is not a feature of the car per se; it is an attribute of the people who use the car. Social network is described as the percentage of people in the respondent's social network - family, friends, neighbors, and/or colleagues - that purchase and drive the described car. This attribute takes values values $20 \%$ and $60 \%$.

The scenarios of our DCE yield a D-efficiency of $93.94 \%$ generated via Doptimal design (see Carlsson \& Martinsson, 2003). The DCE contains 21 unique choice sets, which are assigned to three blocks of 7 choice sets each. Respondents are randomly assigned among the three blocks. Each choice set has two alternatives (high star car and moderate star car) and a status quo alternative (presently available unlabeled car). The respondents were asked to choose one alternative in each choice set. Table 2 shows an instance of the choice sets.

\subsection{Split-sample approach}

This paper implements a split-sample approach through which half of the sample is said that the government is considering the implementation of an environmental regulation. This regulation is described as a policy that would restrict 
Enhancing the informational nudge of energy labels in New Delhi

the number of days a car can be driven weekly unless the car displays the label reflecting the best fuel efficiency performance - very much resembling the Mexican Hoy No Circula. This information was provided to respondents before presenting them to the DCE.

New Delhi's residents are familiar with this type of regulation since a similar policy was implemented in January, April 2016 and again in November, 2019. Under the 2016 and 2019 regulation, cars could circulate depending on the ending number of their license plate. Cars with even numbers could only circulate on even dates, and correspondingly for odd numbers.

Arguably, this regulation provides incentives to drive cars with the best efficiency label. Thus we expect that respondents presented to this regulation have a higher WTP for high star cars than those who are not presented to such a policy.

\subsection{Sampling and data collection}

The DCE was conducted during October to November 2017 in two neighborhoods of New Delhi. We use a multi-stage sampling strategy to select our sample. In the first stage, we select two districts from Delhi, South Delhi and East Delhi. Residents of both districts belong to middle income to high middle income class families. In the second stage, South Delhi and East Delhi are stratified in three sub-districts - Kalkaji, Defence Colony, Hauz Khas in South Delhi; and Gandhi Nagar, Preet Vihar, Vivek Vihar in East Delhi. Within each subdistrict, randomly selected 84 respondents were presented to the DCE, yielding a sample size of 504 respondents. Randomly, half of the respondent within each sub-district, i.e. 42 respondents, were presented to the policy described in section 5.2. Each respondent was presented to 7 choice sets which yields a total of 3,528 individual choice tasks. Each choice set included 3 alternatives yielding 10,584 individual observations. Out of these 10,584 observations, 5,292 individual observations belong to the sample presented policy described in section 5.2 .

\subsection{Comparison of means across split samples}

Table 3 reports mean and standard deviation of the socioeconomic variables characterizing respondents in our two samples. The first column reports descriptive statistics for respondents that were not told about the driving restrictions described in section 5.2. The second column reports descriptive statistics for respondents that were told about the driving restrictions. The third column reports two-tailed t-test statistics on the null hypothesis that the difference in means is zero.

Given the split-sample approach in this study, it is essential that respondents in both samples are as similar as possible in socioeconomic characteristics. Accordingly, the descriptive statistics reported in the first two columns of table 3 and the corresponding t-test statistics suggest that, on average, respondents in both samples are similar when it comes to respondent's age, percentage of male 
Enhancing the informational nudge of energy labels in New Delhi

respondents, marital status of respondent, household size, household annual income, education attainment, and occupation. The only exception is number of cars owned by the household. Respondents in the driving restrictions sample seem to have on average more cars than respondents in the no driving restrictions sample. We highlight that while this difference is statistically significant, the order of magnitude (0.2) is small for practical purposes.

We are less concerned with similarity of our samples to New Delhi's or national's averages. This is the case because we purposely have sampled our respondents from middle income class neighborhoods, and expect them to be wealthier and more educated than the average household. For instance, while people with graduate or higher levels of education represent around $82 \%$ of our samples, they represent $11 \%$ of the national population (MHRD, Government of India, 2016). 9 Also, the average annual household income at the national level is around 0.55 million of Rupees (Business Today, 2019) 10, which is around a third of the average income in our samples

\section{Results}

\subsection{Econometric specifications}

Specifications reported in this section explore the potential average impact of simultaneously implementing a labeling system and driving restrictions in New Delhi ${ }^{11}$ Table 4 reports coefficients obtained via conditional and random parameters logit specifications. For the random parameters specifications, we assume normally distributed parameters for all but the price attribute which is kept constant. Coefficients in table 4 cannot be interpreted as marginal effects but their signs do provide information on the direction of the impacts on individuals' utility.

The first three columns in table 4 report specifications on the sample that was not told about driving restrictions. The last three columns in table 4 report specifications on the sample that was told about driving restrictions.

Focusing on results from the sample that was not informed about driving restrictions, we highlight five features. First, with no exceptions, coefficients' signs are the same across conditional and random parameters specifications i.e. positive for all but the price attribute. Second, with exception of the second best efficiency label, statistical significance remains across specifications - the second best label is a significant level only when estimating a random parameters specification. Third, while point estimates across specifications differ, they remain within the same order of magnitude. Fourth, the statistical significance of most of the standard deviation parameters in the random parameters specification suggests the presence of unobserved heterogeneity that the conditional logit is not fit to handle. Fifth, the random parameters specification yields a

\footnotetext{
${ }^{9}$ Own estimates based on enrollment in school and higher education

${ }^{10}$ Own estimates based on information provided by the Central Statistics Office in India.

${ }^{11}$ In a companion paper, we dig further into the factors behind WTP heterogeneity.
} 
Enhancing the informational nudge of energy labels in New Delhi

substantial improvement in statistical adjustment — as implied by the higher value of the loglikelihood function $(-2,602$ versus $-1,348)$, and the smaller values of the $\mathrm{BIC}(5,274$ versus 2,826$)$ and $\mathrm{AIC}(5,221$ versus 2,728$)$ which weigh the improvement in the likelihood function versus the increase in estimated parameters implicit in the random parameters specification.

With slight differences, the same five features just mentioned apply to specifications on the sample that was informed about driving restrictions.

Given that the five features hold across split samples, we conclude that i) all attributes considered in this DCE are relevant in respondents' utilities; ii) the directions of the effects from the attributes are robust across specifications; and iii) random parameters specifications represent an improvement in statistical fit over the conditional logit specifications. Thus we rely on the random parameters specifications to infer welfare measures for both samples.

We also highlight that, when comparing random parameters specifications across split samples, most coefficients are practically identical —including the price parameter. One important exception is the parameter associated to the best efficiency label which, together with the identical price parameter, implies that the WTP for a car with the best efficiency label differs across samples. We test this intuition and report results from comparisons in table 5.

\subsection{Welfare measures}

Table 5 reports each attribute's marginal WTP as implied by the random parameters logit specifications reported in table 4. The first two columns report numbers for the no driving restrictions sample. These columns, respectively, refer to the WTP estimates expressed in thousands of Rupees, and the WTP estimates expressed in thousands of US dollars ${ }^{12}$ The next two columns in table 5 report corresponding values for the driving restrictions sample. The last column in table 5 reports the p-value of two-tailed t-tests that compare the average WTP across samples. Our discussion focuses on amounts in dollars.

Focusing on the WTP estimates for the no driving restrictions sample, the average marginal WTP for a car with the best efficiency label is estimated at 4.93 thousand USD. The corresponding value for a car with the second best label is around 3.80 thousand USD. To put these numbers in context, keep in mind that, before responding the DCE, individuals were asked to report the price of a car they would buy in the near future. The average of this reported prices is Rupees 12,85,496 equivalent to 19.79 thousand US dollars. That is, the WTP for the best and second best efficiency labels would represent around $25 \%$ and $19 \%$, respectively, of a car's price.

The previous numbers refer to the WTP for a fuel efficiency label. The WTP for efficiency itself is obtained from the parameters associated to the mileage attribute. An extra kilometer per liter is valued at 212 USD. To judge the magnitude of this number, we compare it against the savings in fuel costs over

\footnotetext{
${ }^{12}$ We use a exchange rate of $1 \mathrm{USD}=64.965 \mathrm{INR}$, as average of the observed value from October-November 2017.
} 
Enhancing the informational nudge of energy labels in New Delhi

the lifetime of an average car in New Delhi. Thus, assuming a car with fuel efficiency of $21 \mathrm{kmpl}$ that is driven 12,000 kilometers a year (Gupta, 2018) for an average of 10 years, and a gasoline price of 70 Rupees per litre, the savings on fuel costs would represent 18,181 Rupees which are equivalent to around 280 US dollars. Thus, respondents' WTP for an extra kilometer per litre is in line with 10-year fuel costs savings.

With respect to the two structural attributes in our DCE, the estimated marginal WTP for engine's power is around 2.15 thousand USD when the engine is bigger than 1,500 cc, and around 1.11 thousand USD when the engine is between 1,000 and 1,500 cc. Also, automatic transmission is valued at 1.25 thousand USD more than a car with manual transmission.

Consistently with results reported by Rasouli \& Timmermans (2016), we document that respondents attach a value to the percentage of social network that drives a car similar to theirs. In particular, respondents report an increase in WTP of around 30 US dollars for a car that is driven by $1 \%$ of their social network.

The last column in table 5 shows that, with exception of the best efficiency label, the WTP for attributes do not differ across samples. The lack of differences in WTP across split samples is expected -i.e.driving restrictions should only change the WTP for the best efficiency label. As a car with the second best label is subject to driving restrictions, no increase in WTP for this label should be expected.

As expected, the WTP for the best efficiency label is higher among respondents faced to driving restrictions - 7.48 thousand USD versus 4.93 thousand USD. To judge the magnitude of the change in WTP, it is convenient to interpret such a change as the WTP to avoid potential driving restrictions -i.e. as regulatory costs. By means of a contingent valuation, Blackman et al. (2018) estimate regulatory costs imposed by the Hoy No Circula in Mexico City. Once protest zeros are excluded, they estimate an average WTP of 345 USD a year per car. This number, when multiplied by 8.6 years 13 yields 2.96 thousand US dollars which can be interpreted as the WTP to avoid driving restrictions over the lifetime of an average car in Mexico City. Our estimate of 2.55 thousand USD is in the same order of magnitude than their 2.96 thousand USD.

\subsection{Market share curves}

Similarly to Arora et al. (2019), we use the sample enumeration technique on equation 9 to estimate a market share for alternative $j$ as follows:

$$
S(j)=\frac{\sum_{i}^{n} \operatorname{Prob}\left(V_{i j}=1 \mid X_{j}, \hat{\beta}\right)}{n}
$$

where $\hat{\beta}$ denotes the vector of coefficients estimated via the random parameter logit model and $n$ denotes the number of individuals in the sample. Different market shares are generated by varying the vector of attributes $X_{j}$. Also, when

\footnotetext{
${ }^{13}$ Which is the the average age of a car in Mexico (World Bank 2010.
} 
Enhancing the informational nudge of energy labels in New Delhi

estimating these shares, we assume that individuals choose between their status quo option and an alternative with specific attributes $X_{j}$.

In particular, figure 1 reports two simulated market share functions. Both curves refer to a car that displays the best efficiency label (high star), with fuel efficiency of $20 \mathrm{kmpl}$, engine capacity between 1,000-1,500, with manual transmission and that is driven by $20 \%$ of a respondents' network. The continuous line describes the market share of such a car under no driving restrictions, and the dotted line illustrates the market share under driving restrictions. Figure 1 shows that the market share shifts to the right when respondents are presented to the driving restrictions scenario. This increase in market share is consistent with the higher stated WTP for the best efficiency label under driving restrictions that we have documented through this section. In average, the driving restrictions are associated to an increase in the market share of $5 \%$. For instance, for a price of 25 thousand USD, the share goes from $50 \%$ to $56 \%$; for a price of 40 thousand USD, the share goes from $16 \%$ to $20 \%$.

Figure 2 reports two simulated market share functions as well -under no driving restrictions and under driving restrictions. The car under analysis is identical to the one in figure 1. with the exception that it displays the second best efficiency label (moderate star) instead. The result that figure 2 illustrates is that no shift in market share occurs when respondents are presented to the driving restrictions scenario - which is consistent with the lack of statistical difference in preference parameters for the second best label across split samples.

\section{Conclusion and Policy Implications}

This study documents two results. First, New Delhi's drivers report a WTP for both fuel efficiency and fuel efficiency label. For fuel efficiency, they would pay 212 USD for an extra kilometer per liter. This number falls close to 10-year fuel cost savings (280 USD). On top, they attach a premium of 4.93 thousand USD to the efficiency label - which represents around $25 \%$ of the price of a car they reported to be willing to buy in the near future. These results are in line with findings based on revealed preferences data showing that drivers pay a premium for efficiency labels that goes above and beyond fuel cost savings (see Alberini et al. 2016).

The second result that this study documents is that a labeling system implemented together with driving restrictions may be expected to increase the uptake of efficient cars among New Delhi's car drivers. In particular, respondents' WTP for a car with the best efficiency label goes from 4.93 thousand US dollars to 7.48 thousand US dollars - an increase interpreted as the WTP to avoid driving restrictions. The implicit regulatory costs in this study are similar to those obtained by Blackman et al. (2018) for Mexico City - 2.55 thousand USD versus 2.96 thousand USD.

Results reported in this study are relevant for policy makers aiming to reduce greenhouse gases generated by the transportation sector. This problem is more urgent than ever as recent years have witnessed unprecedented air pollution 
Enhancing the informational nudge of energy labels in New Delhi

episodes in megacities around the world - e.g. New Delhi, Beijing, Mexico.

A caveat of this study is the representativeness. We cannot claim that our sample is representative of all drivers in New Delhi. We focus our attention on car drivers that belong to middle income to high middle-income class families. Arguably, this is the segment of drivers that can afford to buy new cars with better fuel efficiency. While the specific numbers we report represent our sample, we believe, our general conclusion - i.e. a labeling system implemented together with driving restrictions may be expected to increase the uptake of efficient cars holds for car drivers in New Delhi.

With respect to future research, our random parameters specifications point to the presence of unobserved heterogeneity that deserves to be explored. An ongoing project explores respondents' characteristics associated to heterogeneity in preferences. 
Enhancing the informational nudge of energy labels in New Delhi

\section{References}

Achtnicht, M. (2012). German car buyers' willingness to pay to reduce co 2 emissions. Climatic change, 113, 679-697.

Alberini, A., Bareit, M., \& Filippini, M. (2016). What is the effect of fuel efficiency information on car prices? evidence from switzerland. The Energy Journal, 37.

Alberini, A., Di Cosmo, V., \& Bigano, A. (2019). How are fuel efficient cars priced? evidence from eight eu countries. Energy Policy, 134, 110978.

Arora, A., Bansal, S., \& Ward, P. S. (2019). Do farmers value rice varieties tolerant to droughts and floods? evidence from a discrete choice experiment in odisha, india. Water resources and economics, 25, 27-41.

Ben-Akiva, M. E. (1973). Structure of passenger travel demand models. Ph.D. thesis Massachusetts Institute of Technology. URL: http://onlinepubs. trb.org/Onlinepubs/trr/1974/526/526-003.pdf.

Bhattacharya, R. (2014). Boost for electric and hybrid cars with rs 1.5 lakh subsidy. URL: https://indianexpress.com/article/business/companies/ boost-for-electric-and-hybrid-cars-with-rs-1-5-lakh-subsidy/

The Indian Express. Accessed February 28, 2020.

Blackman, A., Alpízar, F., Carlsson, F., \& Planter, M. R. (2018). A contingent valuation approach to estimating regulatory costs: Mexico's day without driving program. Journal of the Association of Environmental and Resource Economists, 5, 607-641.

Blackman, A., \& Qin, P. (2018). How costly are license platebased driving restrictions? contingent valuation evidence from beijing. URL: http://efdinitiative.org/publications/ how-costly-are-license-plate-based-driving-restrictions-contingent-valuation-evidence EfD Discussion Paper Series 18-18. Accessed February 27, 2020.

BP (2018). Statistical review of world energy. URL: https: //www.bp.com/content/dam/bp/business-sites/en/global/ corporate/pdfs/energy-economics/statistical-review/ bp-stats-review-2018-full-report.pdf Accessed February 28, 2020.

BP (2019). Statistical review of world energy. URL: https: //www.bp.com/content/dam/bp/business-sites/en/global/ corporate/pdfs/energy-economics/statistical-review/ bp-stats-review-2019-full-report.pdf Accessed May 16, 2020.

Bureau of Energy Efficiency (2020). Fuel efficiency. URL: https://beeindia. gov.in/content/fuel-efficiency Accessed February 25, 2020. 
Enhancing the informational nudge of energy labels in New Delhi

$\begin{aligned} & \text { Business Today (2019). India's per-capita income rises } \\ & 10 \% \text { to rs. 10,534 a month in fy19. }\end{aligned}$
//www.businesstoday.in/current/economy-politics/
india-per-capita-income-rises-10-to-rs-10534-a-month-in-fy19/
story/352805.html Accessed March 6, 2020.

Carlsson, F., \& Martinsson, P. (2003). Design techniques for stated preference methods in health economics. Health economics, 12, 281-294.

Centre for Science and Environment (2016). Status of air pollution during winter of 2015-16 and the impact of odd-even car rationing scheme on air quality. URL: http://www.indiaenvironmentportal.org.in/files/file/ Air-pollution-and-odd-even-for-SC.pdf Accessed May 29, 2020.

Daziano, R. A., Waygood, E., Patterson, Z., \& Kohlová, M. B. (2017). Increasing the influence of $\mathrm{co} 2$ emissions information on car purchase. Journal of cleaner production, 164, 861-871.

Economic Survey of Delhi (2019). Highlight of economic survey of delhi. URL: http://delhiplanning.nic.in/sites/default/files/Highlights_ English_ofEconomicSurvey_ofDelhi2018-19.pdf Accessed February 25, 2020.

European Commission (2016). Evaluation of directive 1999/94/ec ("the car labelling directive"). URL: https://ec.europa.eu/clima/sites/clima/ files/transport/vehicles/labelling/docs/car_labelling_final_ report20160728_en.pdf Accessed February 26, 2020.

Galarraga, I., Kallbekken, S., \& Silvestri, A. (2020). Consumer purchases of energy-efficient cars: How different labelling schemes could affect consumer response to price changes. Energy Policy, 137, 111181.

Global Fuel Economy Initiative (2020). India's developing automotive fuel economy policy. URL: https://www.globalfueleconomy.org/transport/ gfei/autotool/case_studies/apacific/india/cs_ap_india.asp Accessed February 26, 2020.

Goel, R., \& Pant, P. (2016). Vehicular pollution mitigation policies in delhi. Economic 83 Political Weekly, 51, 41.

Government of India (2018). Statistical year book india 2018. URL: http:// mospi.nic.in/statistical-year-book-india/2018/189 Accessed February $28,2020$.

Goyal, P., \& Sidhartha (2003). Present scenario of air quality in delhi: A case study of cng implementation. Atmospheric Environment, 37, 5423-5431.

Goyal, S., Ghatge, S., Nema, P., \& Tamhane, S. (2006). Understanding urban vehicular pollution problem vis-a-vis ambient air quality-case study of a megacity (delhi, india). Environmental monitoring and assessment, 119, $557-569$. 
Enhancing the informational nudge of energy labels in New Delhi

Gupta, N. (2018). Indian commuters travel 35km/day says survey. URL: https://timesofindia.indiatimes.com/business/india-business/ indian-commuters-travel-35-km/day-says-survey/articleshow/ 63140954.cms Accessed March 6, 2020.

Haab, T. C., \& McConnell, K. E. (2002). Valuing environmental and natural resources: the econometrics of non-market valuation. Edward Elgar Publishing.

Haq, G., \& Weiss, M. (2016). Co2 labelling of passenger cars in europe: Status, challenges, and future prospects. Energy Policy, 95, 324-335.

IQ-Air (2019). World air quality report. URL: https://www.iqair.com/ world-most-polluted-cities/world-air-quality-report-2019-en.pdf Accessed May 30, 2020.

Irfan, U. (2019). The law that's helping fuel delhi's deadly air pollution. URL: https://www.vox.com/science-and-health/2019/11/8/20948348/ delhi-india-air-pollution-quality-cause . Vox. Accessed January 10, 2020.

Jain, M., Anand, B., \& Patwardhan, A. (2018). Appliance labeling and consumer heterogeneity: A discrete choice experiment in india. Applied Energy, 226, 213-224.

Leard, B. (2018). Consumer inattention and the demand for vehicle fuel cost savings. Journal of choice modelling, 29, 1-16.

McFadden, D. (1973). Conditional logit analysis of qualitative choice behavior. Frontiers in Econometrics, (pp. 105-142). URL: https://eml.berkeley. edu/reprints/mcfadden/zarembka.pdf.

McFadden, D., \& Train, K. (2000). Mixed mnl models for discrete response. Journal of applied Econometrics, 15, 447-470.

MHRD, Government of India (2016). Educational statistics at a glance. URL: http://mhrd.gov.in/sites/upload_files/mhrd/files/ statistics/ESG2016_0.pdf Accessed March 6, 2020.

Noblet, C. L., Teisl, M. F., \& Rubin, J. (2006). Factors affecting consumer assessment of eco-labeled vehicles. Transportation Research Part D: Transport and Environment, 11, 422-431.

Olivier, J. G., Schure, K., \& Peters, J. (2017). Trends in global co2 and total greenhouse gas emissions. URL: https://www.pbl.nl/sites/default/files/downloads/ pbl-2017-trends-in-global-co2-and-total-greenhouse-gas-emissons-2017-report_ 2674_0.pdf PBL Netherlands Environmental Assessment Agency. Accessed February 28, 2020. 
Enhancing the informational nudge of energy labels in New Delhi

Rasouli, S., \& Timmermans, H. (2016). Influence of social networks on latent choice of electric cars: a mixed logit specification using experimental design data. Networks and Spatial Economics, 16, 99-130.

Saraswat, Y., \& Bansal, S. (2020). Health effects of sustained exposure to fine particulate matter: Evidence from india. SSRN Discussion Paper, (pp. 1-21).

Schultz, K., Kumar, H., \& Gettleman, J. (2017). In india, air so dirty your head hurts. URL: https://www.nytimes.com/2017/11/08/world/asia/ india-air-pollution.html. The New York Times. Accessed January 09, 2020.

Sharma, M., \& Dikshit, O. (2016). Comprehensive study on green house gases (ghgs) in delhi. URL: http://www.indiaenvironmentportal.org. in/files/file/Comprehensive-Study-on-Green-House-Gases-(GHGs)

-in-Delhi.pdf Report submitted to the Department of Environment Government of National Capital Territory of Delhi and Delhi Pollution Control Committee. Accessed February 28, 2020.

Train, K. E. (2009). Discrete choice methods with simulation. Cambridge university press.

World Bank (2010). Population of vehicles in mexico city's metropolitan area and their emission levels. URL: http: //documents. worldbank.org/curated/en/198561468123558065/ Population-of-vehicles-in-Mexico-Citys-metropolitan-area-and-their-emission-levels Accessed March 5, 2020.

Ziegler, A. (2012). Individual characteristics and stated preferences for alternative energy sources and propulsion technologies in vehicles: A discrete choice analysis for germany. Transportation Research Part A: Policy and Practice, $46,1372-1385$. 


\section{Tables}

Table 1: Choice Sets Attributes, Levels, and expected sign of preference parameter

\begin{tabular}{l|l|l}
\hline Attributes & Levels & $\begin{array}{l}\text { Expected } \\
\text { Sign }\end{array}$ \\
\hline $\begin{array}{l}\text { Mileage (kilometre per } \\
\text { litre, kmpl) }\end{array}$ & $\begin{array}{l}20,24 \text { for high star car, } \\
16,20 \text { for moderate star car, } \\
13 \text { for status qup }\end{array}$ & + \\
\hline Engine Displacement & $\begin{array}{l}\text { Upto 1000cc, 1000-1500cc, More than } \\
1500 \mathrm{cc}\end{array}$ & + \\
\hline Transmission & Manual (0), Automatic (1) & + \\
\hline $\begin{array}{l}\text { Social Network (Market Share } \\
\text { among Family/Friends/ }\end{array}$ & $20 \%, 60 \%$ & + \\
\hline Neighbors/Colleagues) & $\begin{array}{l}10 \%, 20 \%, 30 \%, 40 \%, 50 \% \text { higher than } \\
\text { your reference price }\end{array}$ & - \\
\hline
\end{tabular}


Enhancing the informational nudge of energy labels in New Delhi

Table 2: Example of choice set from the choice experiment of cars

\begin{tabular}{|c|c|c|c|}
\hline Car Attributes & \multicolumn{3}{|c|}{ Choice Set } \\
\hline & $\begin{array}{l}\text { High Star } \\
\text { Car ( Star 4, 5) }\end{array}$ & $\begin{array}{l}\text { Moderate } \\
\text { Star Car } \\
\text { ( Star 3) }\end{array}$ & $\begin{array}{l}\text { Status quo (Presently } \\
\text { Available Car) }\end{array}$ \\
\hline Price & $\begin{array}{l}40 \% \text { of the } \\
\text { reference price }\end{array}$ & $\begin{array}{l}10 \% \text { of the } \\
\text { reference price }\end{array}$ & \multirow{5}{*}{$\begin{array}{l}\text { Status quo } \\
\text { car which has } \\
\text { mileage of } 13 \mathrm{kmpl}\end{array}$} \\
\hline $\begin{array}{l}\text { Mileage } \\
\text { (kilometres per } \\
\text { litre, } \mathrm{kmpl} \text { ) }\end{array}$ & 20 & 16 & \\
\hline Engine Displacement & Upto 1000cc & $1000-1500 \mathrm{cc}$ & \\
\hline Transmission & Automatic & Manual & \\
\hline $\begin{array}{l}\text { Market Share among } \\
\text { Family/Friends/Neighbors/ } \\
\text { Colleagues }\end{array}$ & $60 \%$ & $60 \%$ & \\
\hline $\begin{array}{l}\text { Your Choice } \\
\text { (mark one } \\
\text { alternative) }\end{array}$ & & & \\
\hline
\end{tabular}


Enhancing the informational nudge of energy labels in New Delhi

Table 3: Comparison of means across split samples

\begin{tabular}{|c|c|c|c|c|}
\hline & $\begin{array}{l}\text { No driving } \\
\text { restrictions } \\
\text { (A) }\end{array}$ & $\begin{array}{c}\text { Driving } \\
\text { restrictions } \\
\text { (B) }\end{array}$ & & \\
\hline Characteristic & $\begin{array}{c}\text { Mean } \\
\text { (Std. Dev.) }\end{array}$ & $\begin{array}{c}\text { Mean } \\
\text { (Std. Dev.) }\end{array}$ & $\begin{array}{c}\text { Two-tailed } \\
\text { t test on } \\
\text { (A)-(B) }\end{array}$ & \\
\hline Age (years) & $\begin{array}{c}40.44 \\
(12.63)\end{array}$ & $\begin{array}{c}40.65 \\
(14.34)\end{array}$ & -0.17 & \\
\hline Male ( 1 if male; 0 if female) & $\begin{array}{c}0.60 \\
(0.49)\end{array}$ & $\begin{array}{c}0.54 \\
(0.50)\end{array}$ & 1.26 & \\
\hline Married ( 1 if married; 0 if unmarried) & $\begin{array}{c}0.75 \\
(0.44)\end{array}$ & $\begin{array}{c}0.72 \\
(0.45)\end{array}$ & 0.70 & \\
\hline Household size (number of members) & $\begin{array}{c}4.95 \\
(2.26)\end{array}$ & $\begin{array}{c}5.16 \\
(2.48)\end{array}$ & -0.99 & \\
\hline Annual household Income (Million of Rupees) & $\begin{array}{l}1.53 \\
(0.90)\end{array}$ & $\begin{array}{c}1.62 \\
(0.98)\end{array}$ & -1.08 & \\
\hline \multicolumn{5}{|l|}{ Education (proportion) } \\
\hline High School & $\begin{array}{c}0.17 \\
(0.37)\end{array}$ & $\begin{array}{c}0.15 \\
(0.35)\end{array}$ & 0.62 & \\
\hline Graduate or higher & $\begin{array}{c}0.81 \\
(0.39)\end{array}$ & $\begin{array}{c}0.83 \\
(0.37)\end{array}$ & -0.59 & \\
\hline Other & $\begin{array}{c}0.02 \\
(0.14)\end{array}$ & $\begin{array}{c}0.02 \\
(0.14)\end{array}$ & 0.00 & \\
\hline \multicolumn{5}{|l|}{ Occupation (proportion) } \\
\hline Professional/Service & $\begin{array}{c}0.48 \\
(0.49)\end{array}$ & $\begin{array}{c}0.44 \\
(0.49)\end{array}$ & 0.91 & \\
\hline Business & $\begin{array}{c}0.32 \\
(0.46)\end{array}$ & $\begin{array}{c}0.30 \\
(0.46)\end{array}$ & 0.49 & \\
\hline Student & $\begin{array}{c}0.07 \\
(0.25)\end{array}$ & $\begin{array}{c}0.11 \\
(0.31)\end{array}$ & -1.59 & \\
\hline Not Working & $\begin{array}{c}0.11 \\
(0.31)\end{array}$ & $\begin{array}{c}0.15 \\
(0.35)\end{array}$ & -1.35 & \\
\hline Other & $\begin{array}{c}0.02 \\
(0.14)\end{array}$ & $\begin{array}{c}0.00 \\
(0.00)\end{array}$ & $2 . .27$ & $* *$ \\
\hline Cars owned by the household (number) & $\begin{array}{c}1.50 \\
(1.14)\end{array}$ & $\begin{array}{c}1.71 \\
(1.17)\end{array}$ & -2.04 & $* *$ \\
\hline Number of respondents & 252 & 252 & & \\
\hline
\end{tabular}

** denotes that null hypothesis is rejected with $95 \%$ of confidence. 
Enhancing the informational nudge of energy labels in New Delhi

Table 4: Econometric specification on respondents' stated choices

\begin{tabular}{|c|c|c|c|c|c|c|}
\hline \multirow{3}{*}{ Attribute } & \multicolumn{3}{|c|}{ No driving restrictions } & \multicolumn{3}{|c|}{ Driving restrictions } \\
\hline & \multirow[t]{2}{*}{$\begin{array}{l}\text { Conditional } \\
\text { Logit }\end{array}$} & \multicolumn{2}{|c|}{$\begin{array}{l}\text { Random Param- } \\
\text { eters Logit }\end{array}$} & \multirow[t]{2}{*}{$\begin{array}{l}\text { Conditional } \\
\text { Logit }\end{array}$} & \multicolumn{2}{|c|}{$\begin{array}{l}\text { Random Param- } \\
\text { eters Logit }\end{array}$} \\
\hline & & Mean & SD & & Mean & SD \\
\hline High Star Label & $\begin{array}{l}0.487^{* *} \\
(0.23)\end{array}$ & $\begin{array}{l}1.987^{* * * *} \\
(0.32)\end{array}$ & $\begin{array}{l}-0.04710 \\
(0.19)\end{array}$ & $\begin{array}{l}1.114^{* * *} \\
(0.23)\end{array}$ & $\begin{array}{l}2.722^{* * *} \\
(0.36)\end{array}$ & $\begin{array}{l}1.562^{* * *} \\
(0.21)\end{array}$ \\
\hline Moderate Star Label & $\begin{array}{l}0.054 \\
(0.18)\end{array}$ & $\begin{array}{l}1.521^{* * *} \\
(0.26)\end{array}$ & $\begin{array}{l}0.670^{* * *} \\
(0.15)\end{array}$ & $\begin{array}{l}0.204 \\
(0.17)\end{array}$ & $\begin{array}{l}1.575^{* * *} \\
(0.27)\end{array}$ & $\begin{array}{l}0.189 \\
(0.32)\end{array}$ \\
\hline Mileage (kmpl) & $\begin{array}{l}0.039^{*} \\
(0.02)\end{array}$ & $\begin{array}{l}0.0853^{* *} \\
(0.04)\end{array}$ & $\begin{array}{l}0.419^{* * * *} \\
(0.04)\end{array}$ & $\begin{array}{l}0.0184 \\
(0.02)\end{array}$ & $\begin{array}{l}0.0803^{* *} \\
(0.04)\end{array}$ & $\begin{array}{l}0.388^{* * * *} \\
(0.03)\end{array}$ \\
\hline Engine (More than $1500 \mathrm{cc}$ ) & $\begin{array}{l}0.588^{* * *} \\
(0.01)\end{array}$ & $\begin{array}{l}0.867^{* * *} \\
(0.17)\end{array}$ & $\begin{array}{l}1.471^{* * *} \\
(0.26)\end{array}$ & $\begin{array}{l}0.345^{* * *} \\
(0.01)\end{array}$ & $\begin{array}{l}0.532^{* * *} \\
(0.18)\end{array}$ & $\begin{array}{l}-1.374^{* * *} \\
(0.25)\end{array}$ \\
\hline Engine (1000- $1500 \mathrm{cc})$ & $\begin{array}{l}0.358^{* * *} \\
(0.09)\end{array}$ & $\begin{array}{l}0.450^{* * *} \\
(0.12)\end{array}$ & $\begin{array}{l}0.244 \\
(0.23)\end{array}$ & $\begin{array}{l}0.287^{* * *} \\
(0.09)\end{array}$ & $\begin{array}{l}0.503^{* * *} \\
(0.13)\end{array}$ & $\begin{array}{l}-0.2090 \\
(0.24)\end{array}$ \\
\hline Automatic Transmission & $\begin{array}{l}0.272^{* * *} \\
(0.08)\end{array}$ & $\begin{array}{l}0.506^{* * *} \\
(0.13)\end{array}$ & $\begin{array}{l}0.801^{* * *} \\
(0.24)\end{array}$ & $\begin{array}{l}0.222^{* * *} \\
(0.08)\end{array}$ & $\begin{array}{l}0.529^{* * *} \\
(0.14)\end{array}$ & $\begin{array}{l}-1.097^{* * *} \\
(0.23)\end{array}$ \\
\hline Network (\%) & $\begin{array}{l}0.009^{* * *} \\
(0.002)\end{array}$ & $\begin{array}{l}0.0118^{* * *} \\
(0.003)\end{array}$ & $\begin{array}{l}0.0216^{* * *} \\
(0.004)\end{array}$ & $\begin{array}{l}0.0046^{* * *} \\
(0.002)\end{array}$ & $\begin{array}{l}0.0029 \\
(0.003)\end{array}$ & $\begin{array}{l}-0.021 * * * \\
(0.004)\end{array}$ \\
\hline Price (Rupees/1,000) & $\begin{array}{l}-0.002^{* * * *} \\
(0.0001) \\
\end{array}$ & $\begin{array}{l}-0.006^{* * *} \\
(0.0004)\end{array}$ & & $\begin{array}{l}-0.002^{* * *} \\
(0.0002) \\
\end{array}$ & $\begin{array}{l}-0.006^{* * *} \\
(0.0004)\end{array}$ & \\
\hline Log Likelihood & -1669.406 & -1348.93 & & -1623.436 & -1287.591 & \\
\hline AIC & 3354.811 & 2727.854 & & 3262.872 & 2605.181 & \\
\hline BIC & 3407.403 & 2826.464 & & 3315.464 & 2703.79 & \\
\hline LR chi2 & $537.09^{* * *}$ & $640.96^{* * *}$ & & $629.03^{* * *}$ & $671.69^{* * *}$ & \\
\hline Respondents & 252 & 252 & & 252 & 252 & \\
\hline Observations & 5,292 & 5,292 & & 5,292 & 5,292 & \\
\hline
\end{tabular}

Note: Standard Errors are reported in parenthesis; ${ }^{*},{ }^{*}$ and ${ }^{* * *}$ denote that the parameters are significant at $10 \%, 5 \%$ and $1 \%$ level respectively.

Table 5: Marginal Willingness to Pay implied by random parameters logit specifications

\begin{tabular}{|c|c|c|c|c|c|}
\hline \multirow[b]{2}{*}{ Attributes } & \multicolumn{2}{|c|}{ No driving restrictions } & \multicolumn{2}{|c|}{ Driving restrictions } & \multirow[b]{2}{*}{$\begin{array}{l}\text { p-value of } \\
\text { two-tailed } \\
\text { t-test on } \\
(A)-(B)\end{array}$} \\
\hline & $\begin{array}{l}\text { MWTP } \\
(\mathbf{1}, 000 \\
\text { Rupees })\end{array}$ & $\begin{array}{l}\text { MWTP } \\
(1,000 \\
\text { USD) } \\
(A) \\
\end{array}$ & $\begin{array}{l}\text { MWTP } \\
(1,000 \\
\text { Rupees })\end{array}$ & $\begin{array}{l}\text { MWTP } \\
(1,000 \\
\text { USD) } \\
\text { (B) } \\
\end{array}$ & \\
\hline High Star Label & $\begin{array}{l}320.69^{* * *} \\
(47.91)\end{array}$ & $\begin{array}{l}4.936^{* * *} \\
(0.74)\end{array}$ & $\begin{array}{l}86.00^{* * *} \\
(59.91)\end{array}$ & $\begin{array}{l}7.481^{* * * *} \\
(0.92)\end{array}$ & 0.0156 \\
\hline Moderate Star Label & $\begin{array}{l}245.46^{* * *} \\
(38.50)\end{array}$ & $\begin{array}{l}3.778^{* * *} \\
(0.59)\end{array}$ & $\begin{array}{l}281.17^{* * *} \\
(43.67)\end{array}$ & $\begin{array}{l}4.328^{* * * *} \\
(0.67)\end{array}$ & 0.2699 \\
\hline Mileage $(\mathrm{kmpl})$ & $\begin{array}{l}13.76^{* * *} \\
(5.80)\end{array}$ & $\begin{array}{l}0.212^{* * *} \\
(0.09)\end{array}$ & $\begin{array}{l}14.34^{* * *} \\
(6.93)\end{array}$ & $\begin{array}{l}0.221^{* *} \\
(0.11)\end{array}$ & 0.4744 \\
\hline Engine (More than $1500 \mathrm{cc}$ ) & $\begin{array}{l}139.90^{* * *} \\
(27.15)\end{array}$ & $\begin{array}{l}2.154^{* * *} \\
(0.42)\end{array}$ & $\begin{array}{l}94.95^{* * *} \\
(31.93)\end{array}$ & $\begin{array}{l}1.462^{* * * *} \\
(0.49)\end{array}$ & 0.1414 \\
\hline Engine $(1000-1500 \mathrm{cc})$ & $\begin{array}{l}72.71^{* * *} \\
(20.05)\end{array}$ & $\begin{array}{l}1.119^{* * * *} \\
(0.31)\end{array}$ & $\begin{array}{l}89.83^{* * * *} \\
(23.43)\end{array}$ & $\begin{array}{l}1.383^{* * * *} \\
(0.36)\end{array}$ & 0.2891 \\
\hline Automatic Transmission & $\begin{array}{l}81.67^{* * *} \\
(19.89)\end{array}$ & $\begin{array}{l}1.257^{* *} \\
(0.31)\end{array}$ & $\begin{array}{l}94.40^{* * *} \\
(24.22)\end{array}$ & $\begin{array}{l}1.453^{* * *} \\
(0.37)\end{array}$ & 0.3422 \\
\hline Network (\%) & $\begin{array}{l}1.90^{* * *} \\
(0.51)\end{array}$ & $\begin{array}{l}0.029^{* * * *} \\
(0.01)\end{array}$ & $0.51(0.57)$ & $\begin{array}{l}0.008 \\
(0.01)\end{array}$ & 0.0380 \\
\hline
\end{tabular}

Standard Errors reported in parenthesis: $*, * *$ and $* * *$ denote that the parameters are significant at $10 \%, 5 \%$ and $1 \%$ level, respectively. 


\section{Figures}

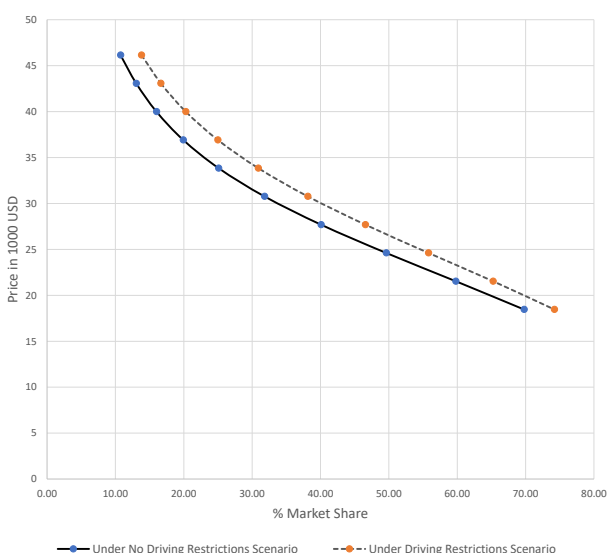

Figure 1: Simulated market share curves for a best efficiency label (High Star) car with mileage 20 per $\mathrm{Km}$, engine capacity 1000 - 1500, manual transmission and network $20 \%$ vis a vis status quo option 


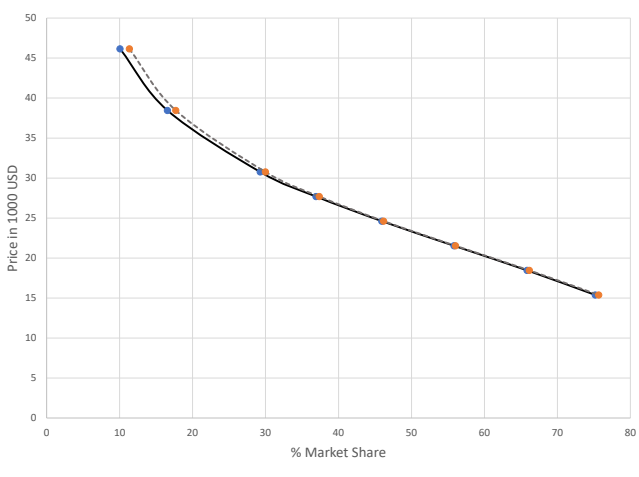

Figure 2: Simulated market share curves for a best efficiency label (Moderate Star) car with mileage 20 per Km, engine capacity 1000 - 1500, manual transmission and network $20 \%$ vis a vis status quo option 